\title{
Obesity and ARDS: Opportunity for Highly Personalized Mechanical Ventilation?
}

Obesity is more and more prevalent in industrialized countries and, to a lesser extent, in developing countries. ${ }^{1}$ It is a worldwide public issue for health-care practitioners in numerous clinical activities as well as for public health decisions. ${ }^{2,3}$ Obesity affects many aspects of the care delivered to the patient. Among these aspects, mechanical ventilation may be one of the most challenging to handle, either in the operating theater or in the ICU. This could be of particular importance for patients with both severe obesity and ARDS, a population in which only limited data are available. ${ }^{4}$

In the current issue of RESPIRATORY CARE, Tlayjeh et $\mathrm{al}^{5}$ present very valuable results of a post hoc analysis of the OSCILLATE trial, focused on the impact of body mass index (BMI) on the mortality of subjects with ARDS. The OSCILLATE trial included 548 subjects with moderate or severe ARDS, randomized either to a conventional highPEEP ventilation strategy or to high-frequency oscillatory ventilation. ${ }^{6,7}$ Overall, no differences in mortality rates were observed across all BMI strata. Moreover, the association of high-frequency oscillatory ventilation with inhospital mortality was not affected by BMI strata. The study had some limitations as acknowledged by the authors. Mainly, only $82 \%$ of the subjects enrolled in the OSCILLATE trial could be included in the post hoc analysis and patients who were obese and with an actual body weight of $>1 \mathrm{~kg}$ per centimeter in height were excluded from the OSCILLATE trial. ${ }^{5}$

The fact that subjects with ARDS and who were obese (BMI, $30-39.9 \mathrm{~kg} / \mathrm{m}^{2}$ ) and severely obese (BMI $>40 \mathrm{~kg} /$ $\mathrm{m}^{2}$ ) had similar mortality rates to subjects with ARDS and of normal weight is very important because it confirms previous results from other groups. ${ }^{8-11}$ From our point of view, such a result should not imply that patients who are obese should be uniformly managed as patients with ARDS of normal weight, but as an opportunity to develop personalized ventilatory strategies that aim to specifically im-

The authors have disclosed no conflicts of interest.

Correspondence: Jean-Luc Diehl MD, Medical Intensive Care Unit, Hôpital Européen Georges Pompidou, Assistance Publique-Hôpitaux de Paris, 20 Rue Leblanc, 75015, Paris, France. E-mail: jean-luc.diehl@aphp.fr.

DOI: $10.4187 /$ respcare. 07292 prove the prognosis of patients with combined ARDS and obesity. Indeed, one should keep in mind the very specific mechanics of such patients as well as results of a post hoc analysis of the ALVEOLI study, ${ }^{10}$ which demonstrated a benefit of a high-PEEP strategy in subjects with ARDS who were obese.

See the Original Study on Page 1042

Patients with ARDS who are obese and severely obese are characterized by excessively high pleural pressures, which leads to negative transpulmonary pressures, whereas chestwall compliance remains generally within the normal range. ${ }^{4}$ Because pleural pressure can be estimated by monitoring esophageal pressure, it provides a good opportunity to test the hypothesis that PEEP settings that aim to obtain a positive end-expiratory transpulmonary pressure could improve the prognosis of patients with ARDS who are obese or severely obese. Furthermore, from a safety perspective, such esophageal pressure monitoring allows calculation of the end-inspiratory transpulmonary pressure (as a reflect of the posterior dependent lung areas, submitted to the weight of the damaged lung) and end-inspiratory transpulmonary pressure estimated from the elastance ratio of the chest wall to the respiratory system (as a reflect of the anterior nondependent lung areas, not submitted to the weight of the damaged lung), even if the latter has not been fully validated in patients with ARDS and who are obese and severely obese. ${ }^{12}$

It was recently shown that titrating PEEP with an esophageal pressure-guided strategy was not associated with a mortality benefit compared with an empirical high-PEEP strategy (derived from the OSCILLATE trial) in a general ARDS population. ${ }^{13}$ Interestingly, the mean actual body weight was 84.0 (72.0 to only 105.0$) \mathrm{kg}$ in the experimental group (esophageal pressure-guided strategy), with a mean PEEP level difference between the 2 groups of only $1.5 \mathrm{~cm} \mathrm{H}_{2} \mathrm{O}$. One can suppose that an esophageal pressureguided strategy could have led to more positive clinical results in a homogeneous group of subjects with ARDS who were obese or severely obese, perhaps defined by a BMI lower limit of 35 or $40 \mathrm{~kg} / \mathrm{m}^{2}$.

Another important feature to take into account is the frequent occurrence of an airway closure phenomenon in 


\section{EDITORIALS}

patients who are obese and severely obese. ${ }^{14}$ Setting PEEP above the airway opening pressure, if present, could lead to more exact calculations of expiratory transpulmonary pressures as well as to avoid cyclic small airways closing and reopening. Beside esophageal and airway pressure monitoring, electrical impedance tomography could be of great interest in patients with ARDS who are obese and severely obese, both for measuring global and regional changes in lung volume in response to different PEEP settings and also to detect or confirm an airway closure phenomenon. ${ }^{4,15}$

Also, it is conceivable that the pattern of body-fat distribution (abdominal vs general) could also be an important factor to take into account, in addition to the absolute BMI value. In this way, monitoring of abdominal pressure in response to various respiratory settings could be a means to avoid an excessive rise in patients with low abdominal compliance. ${ }^{16}$ Such a monitoring can be achieved by means of either gastric or bladder pressure monitoring.

We now have the opportunity to better analyze, at the bedside, the respiratory mechanics and ventilation of patients with ARDS who are obese and severely obese. Such monitoring could help implement personalized mechanical ventilator settings and evaluate, on a large scale, specific ventilator strategies that aim to improve the prognosis of such patients with ARDS. If such monitoring is not available at the bedside, then clinicians should be strongly encouraged to use high-PEEP strategies in patients with ARDS who are obese and severely obese.

Jean-Luc Diehl

Medical Intensive Care Unit

Hôpital Européen Georges Pompidou Assistance Publique-Hôpitaux de Paris Paris, France

Institut National de la Santé et de la Recherche Médicale

Unité Mixte de Recherche_S1140

Innovations Thérapeutiques en Hémostase

Faculté des Sciences Pharmaceutiques et Biologiques Paris Descartes University Paris, France

\section{Damien Vimpere} Emmanuel Guérot

Medical Intensive Care Unit Hôpital Européen Georges Pompidou Assistance Publique-Hôpitaux de Paris Paris, France

\section{REFERENCES}

1. Flegal KM, Kruszon-Moran D, Carroll MD, Fryar CD, Ogden CL. Trends in obesity among adults in the United States, 2005 to 2014. JAMA 2016;315(21):2284-2291.
2. Arterburn DE, Maciejewski ML, Tsevat J. Impact of morbid obesity on medical expenditures in adults. Int J Obes (Lond) 2005;29(3): 334-339.

3. Grieve E, Fenwick E, Yang HC, Lean M. The disproportionate economic burden associated with severe and complicated obesity: a systematic review: economic burden of severe obesity. Obes Rev 2013;14(11):883-894.

4. Fumagalli J, Santiago RRS, Teggia Droghi M, Zhang C, Fintelmann FJ, Troschel FM, et al.; Lung Rescue Team Investigators. Lung recruitment in obese patients with acute respiratory distress syndrome. Anesthesiology 2019;130(5):791-803.

5. Tlayjeh H, Arabi YM, Ferguson ND, Zhou Q, Lamontagne F, Arroliga $\mathrm{A}$, et al. Body mass index and mortality in subjects with ARDS: post-hoc analysis of the OSCILLATE Trial. Respir Care 2019;64(9):1042-1048.

6. Meade MO, Cook DJ, Guyatt GH, Slutsky AS, Arabi YM, Cooper DJ, et al.; Lung Open Ventilation Study Investigators. Ventilation strategy using low tidal volumes, recruitment maneuvers, and high positive end-expiratory pressure for acute lung injury and acute respiratory distress syndrome: a randomized controlled trial. JAMA 2008;299(6):637-645.

7. Ferguson ND, Cook DJ, Guyatt GH, Mehta S, Hand L, Austin P, et al.; OSCILLATE Trial Investigators, Canadian Critical Care Trials Group. High-frequency oscillation in early acute respiratory distress syndrome. N Engl J Med 2013;368(9):795-805.

8. Gong MN, Bajwa EK, Thompson BT, Christiani DC. Body mass index is associated with the development of acute respiratory distress syndrome. Thorax 2010;65(1):44-50.

9. Chiumello D, Colombo A, Algieri I, Mietto C, Carlesso E, Crimella $\mathrm{F}$, et al. Effect of body mass index in acute respiratory distress syndrome. Br J Anaesth 2016;116(1):113-121.

10. Bime C, Fiero M, Lu Z, Oren E, Berry CE, Parthasarathy S, Garcia JGN. High positive end-expiratory pressure is associated with improved survival in obese patients with acute respiratory distress syndrome. Am J Med 2017;130(2):207-213.

11. De Jong A, Cossic J, Verzilli D, Monet C, Carr J, Conseil M, et al. Impact of the driving pressure on mortality in obese and non-obese ARDS patients: a retrospective study of 362 cases. Intensive Care Med 2018;44(7):1106-1114.

12. Yoshida T, Amato MBP, Grieco DL, Chen L, Lima CAS, Roldan $\mathrm{R}$, et al. Esophageal manometry and regional transpulmonary pressure in lung injury. Am J Respir Crit Care Med 2018;197(8): 1018-1026.

13. Beitler JR, Sarge T, Banner-Goodspeed VM, Gong MN, Cook D, Novack V, et al.; EPVent-s Study Group. Effect of titrating positive end-expiratory pressure (PEEP) with an esophageal pressure-guided strategy vs an empirical high $\mathrm{PEEP}-\mathrm{FiO}_{2}$ strategy on death and days free from mechanical ventilation among patients with acute respiratory distress syndrome: a randomized clinical trial. JAMA 2019; 321(9):846-857.

14. Chen L, Del Sorbo L, Grieco DL, Shklar O, Junhasavasdikul D, Telias I, et al. Airway closure in acute respiratory distress syndrome: an underestimated and misinterpreted phenomenon. Am J Respir Crit Care Med 2018;197(1):132-136.

15. Sun XM, Chen GQ, Zhou YM, Yang YL, Zhou JX. Airway closure could be confirmed by electrical impedance tomography. Am J Respir Crit Care Med 2018;197(1):138-141.

16. Bein T. Driving pressure in obese ventilated patients: another brick in the (chest) wall. Intensive Care Med 2018;44(8):1349-1351. 